Journal of Advanced Research in Fluid Mechanics and Thermal Sciences

Journal homepage: www.akademiabaru.com/arfmts.html ISSN: $2289-7879$

\title{
The Effects of Multiple Swirl Generator Inlets Circumferential Distribution to a Liquid Fuelled Ultra-High Swirl Flameless Combustion Characteristics
}

\author{
Adam Kasani ${ }^{1,2}$, Mazlan Abdul Wahid ${ }^{1,}{ }^{*}$, Ahmad Dairobi Ghazali ${ }^{1}$, Mohammed Bashir \\ Abdulrahman ${ }^{1}$ \\ High Speed Reacting Flow (HiREF) Laboratory, Faculty of Engineering, School of Mechanical Engineering, Universiti Teknologi Malaysia, Malaysia \\ Fakulti Kejuruteraan Mekanikal dan Pembuatan, Universiti Tun Hussein Onn Malaysia, Malaysia
}

\section{ARTICLE INFO}

\section{Article history:}

Received 27 July 2020

Received in revised form 25 September 2020

Accepted 28 September 2020

Available online 16 October 2020
Keywords:

Flameless combustion; swirl flow; liquid fuel; ethanol

\section{ABSTRACT}

\begin{abstract}
This paper presents the experimental results of a simple cylindrical shaped, liquid fuelled flameless combustor which utilizes ultra-high swirl flow in the combustion process. 4 different swirl generator inlet configurations were tested in this work. Ethanol fuel were used during flameless mode. The experiments were conducted at equivalence ratio $(\Phi=1)$, with the flow rate of fuel set at $30 \mathrm{ml} / \mathrm{min}$, and flow rate of air at $400 \mathrm{scfh}$. The results revealed that by using all 12 tangential air inlets (swirl generator injectors), the swirl strength was reduced through evenly distributing the position of the injectors circumferentially. As a result, the combustor successfully suppressed the emission of $\mathrm{NO}_{\mathrm{x}}$ and $\mathrm{CO}$ to zero ppm for both gasses. It was also reported that flameless mode was established in all configurations, regardless of the swirl strength.
\end{abstract}

\section{Introduction}

In the last few decades, the world's energy usage has been causing pollution and global warming at an alarming rate $[1,2]$. The depletion of fossil fuels are also causing energy crisis worldwide. Over $90 \%$ of world's energy consumption is supplied by the combustion of fossil fuels [3] and $20 \%$ came from transportation [4]. Thus, the race of searching for alternative fuels [5], improving the efficiency of combustion process and clean energy generating system resulted into the discovery of various new technologies and combustion techniques as a counter measure for global warming. One of the most promising findings is called flameless combustion. Flameless combustion or Flameless Oxidation $\left(\mathrm{FLOX}^{\circledR}\right)$ is a unique combustion technology that was first discovered in the late eighties [6]. It can be defined as a complete combustion process without the presence of visible flame [7].

\footnotetext{
* Corresponding author.

E-mail address: mazlan@fkm.utm.my

https://doi.org/10.37934/arfmts.76.2.6574
} 
One of the requirements of establishing flameless mode is to increase the temperature of the reaction zone to be above the auto ignition temperature of the fuel mixture. Aided by strong recirculation of hot flue gas inside the combustion chamber, a conventional flame can be transformed into flameless combustion $[8,9]$.

It was developed for the purpose of $\mathrm{NO}_{x}$ abatement in the combustion process [10]. Flameless combustion is proven to produce extremely low level of NOx and CO gas [11]. This is due to the nature of flameless combustion where the front flame is absent throughout the whole reaction zone of the combustion reaction. Without the presence of flame front, the temperature inside the reaction zone was suppressed below the temperature of the thermal $\mathrm{NO}_{\mathrm{x}}$ formation, which is the main contributor of $\mathrm{NO}_{\mathrm{x}}$ emission for most combustion processes $[12,13]$. This also contributed into lower combustion operating temperature and peak temperature inside the combustion chamber. As a result, the cost of maintenance can be significantly reduced due to the increased machine lifetime in long term application [14].

Another advantage and unique characteristics of flameless combustion is the condition where almost non-existence of temperature fluctuation inside the combustion chamber. This is due to the dilution effect that comes with strong recirculation of hot flue gas. This as a matter of fact, made it looked like the temperature field or temperature profile inside the combustion chamber to be uniform and homogenous throughout the whole volume of the combustion chamber. Yang et al., defined the temperature uniformity ratio $\left(R_{u}\right)$ as shown in Eq. (1) [15]

$R_{u}=\left[\sum\left(\frac{T-\bar{T}}{\bar{T}}\right)^{2}\right]^{\frac{1}{2}}$

where

$R_{u}=$ ratio of temperature uniformity

$T=$ measured temperature at any point in Kelvin

$\bar{T}$ =average temperature

As $R_{u}$ approaches zero, the fluctuation of temperature also becomes smaller. In other words, the temperature profile inside the combustion chamber is more uniformed as the value of $R_{u}$ decreases and approaches zero [16]. Previous studies have reported uniform temperature distributions for flameless combustion [16-19].

Previous studies concerning flameless combustion were mainly focused on the use of gaseous fuel [20]. This is due to the homogeneous mixture produced from the mixing process of gaseous fuel and air. A homogeneous reactant mixture was found to be exceptionally advantageous in establishing flameless mode [21,22]. Contrary to gaseous fuel, by mixing liquid fuel with air, a heterogeneous reactant mixture is produced. This causes extra energy is required in changing the phase of the fuel from liquid to gas, thus increasing the reaction time. As a result, this will allow the liquid fuel to silt at the bottom of the rig, thus reducing the efficiency of the process, and obstructing the production of flameless mode. Thus, a much more complex mixing method that involves atomization and vaporization of liquid fuel through jet spray is needed to produce a relatively homogenous mixture for combustion process $[20,23,24]$.

In this particular work, swirl flow was introduced into the combustion process to improve the rate of reactants mixing, increase the entrainment of fuel mixture, and to improve the efficiency of the rate of combustion inside the combustion chamber [21]. Swirl flow is a type of flow that contains both axial and tangential components (vortex flow) in the velocity vector [25]. One of the approaches for calculating geometric swirl number was introduced by Guo et al., and was also adapted in another 
study by Guo et al., as shown in Eq. (2). The similarity of the geometrical design concept between the previously mentioned researches to the test section in this research consists of the use of multiple tangential inlets to introduce swirl flow into a laminar axial flow. Eq. (2) not only took into account the mass flow rate ratio of the tangential injections and the axial injections, but also the number of tangential injectors and the degree of tangential inlet being injected into the main test section $[26,27]$. Thus, the geometrical swirl in this work is calculated using Eq. (2) as shown below.

$S_{g}=\left(\frac{m_{t}}{m_{T}}\right)^{2}\left(\frac{D}{d}\right)^{2} \frac{\sin \theta}{n}$

where,

$m_{t}=$ total mass flow rate through the tangential injector

$m_{T}=$ total mass flow rate in the chamber

$D=$ diameter of the chamber

$d=$ diameter of the tangential injector

$\theta=$ injection angle

$n=$ number of injectors

\section{Methodology}

A new type of flameless combustor was developed in the High-Speed Reacting Flow (HiREF) research laboratory here in Universiti Teknologi Malaysia. The liquid-fueled ultra-high swirl flameless combustor was designed with the objective of simplifying the structural geometry of a liquid fueled flameless combustor and the overall combustion process to achieve flameless mode. It can be seen that most of the designs in previous works had complex geometries and were also quite miniscule compared to industrial scale [14]. Thus, a semi-industrial scale liquid fueled flameless combustor was designed using simple cylindrical geometry to minimize manufacturing cost and to prove that geometric structure has minimal effect on the success rate of achieving flameless mode.

The combustor was installed with 12 tangential air inlets that acted as swirl generators. All 12 air inlets are divided into three groups of four tangential inlets as follows. For the group (SG1), the injectors are located near the exhaust channel, whereas for the group (SG2) is located at the middle of the length of the combustion chamber, while for the group (SG3), located near the inlet flank. Each group has four tangential inlets which are evenly distributed along the circumference of the chamber at the position of 12 o'clock, 3 o'clock, 6 o'clock, and 9 o'clock respectively. The positions of the tangential air inlets are represented in Figure 1.

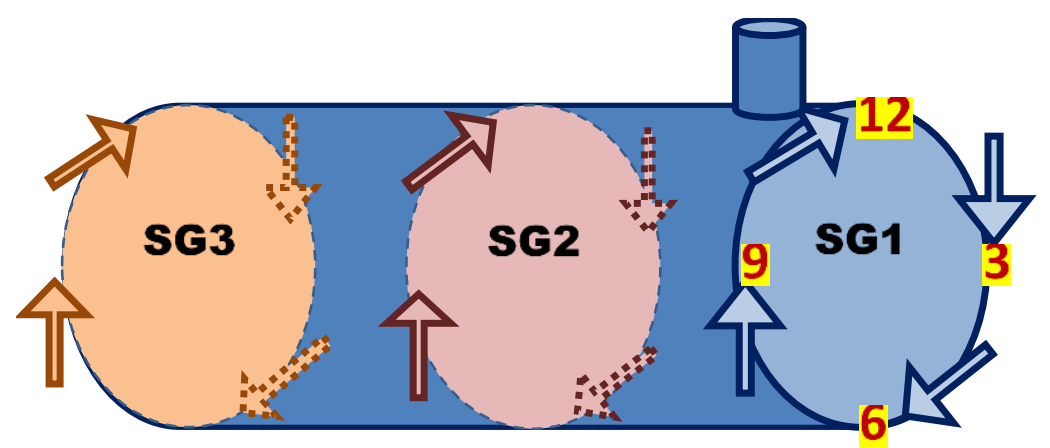

Fig. 1. Tangential inlet position 
In this work, the number of activated tangential injectors were selected by activating only one injector from each injector groups. This is followed by increasing the number of activated injectors by one from every group. This process is repeated until all 12 tangential air injectors were activated. To summarize this step, the activated tangential injectors are listed as in Table 1.

\section{Table 1}

Positions of activated tangential air inlet injectors for study case case $(A \sim D)$ at equivalence ratio $(\Phi): 1$ Tangential air inlet configuration Number of swirl injectors, (n) Geometrical Swirl number, $\left(\mathrm{S}_{\mathrm{g}}\right)$

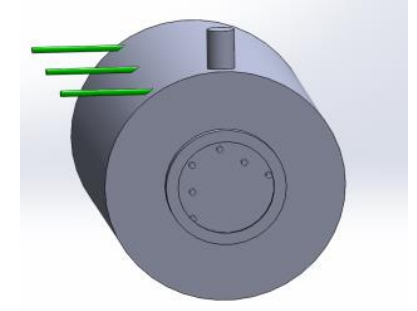
3 $\approx 600$

A

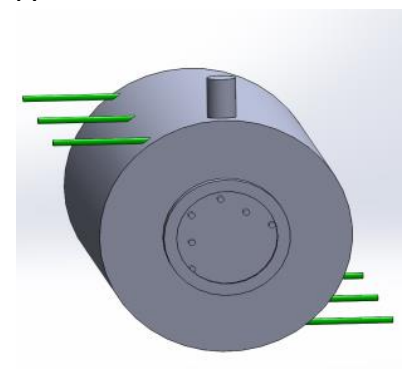

B

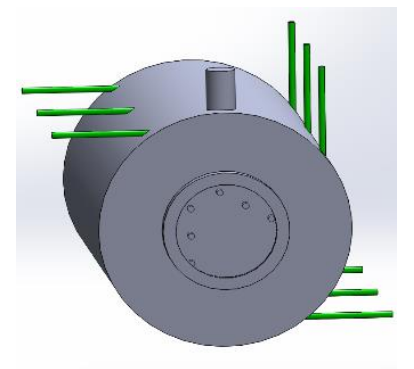

C

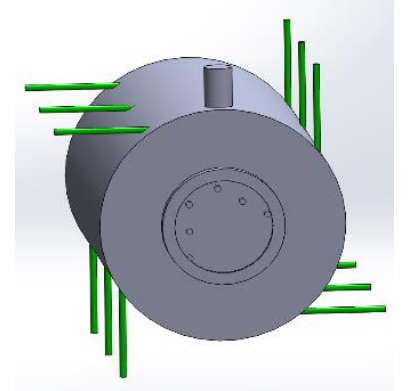

The objective of this experiment is to investigate the effects of changes in swirl strength or geometrical swirl number $\left(S_{g}\right)$ due to the changes in the numbers of activated tangential inlets to the combustion characteristics of flameless combustion. It is also important to note that, the changes in the amount of activated tangential air inlets also represents the changes in the arrangement of the 
swirl generator injectors (tangential air inlet) distribution, as shown in Table 1. In this experiment, the equivalence ratio was at $(\Phi=1)$ where the flow rate of both combustion air and the liquid fuel were kept constant at $30 \mathrm{ml} / \mathrm{min}$ and $400 \mathrm{scfh}$, respectively. This step is to ensure the isolation of swirl changes due to changes in the reactant mixture.

\section{Results and Discussion}

According to Eq. (2), the number of injectors is inversely proportional to the geometric swirl number $\left(\mathrm{S}_{\mathrm{g}}\right)$ that represents the strength of the swirl flow inside the combustion chamber. This translates into, as the number of injectors increases, the swirl number decreases, as shown in Table 1. It is known that swirl flow improves the mixing of reactants, longer entrainment of flue gas, increases the recirculation of flue gas inside the combustion chamber, and improves the combustion reaction rate [28-30]. Thus, it is a perfectly logical hypothesis to assume that as the swirl increases, the production of $\mathrm{NO}_{\mathrm{x}}$ and $\mathrm{CO}$ gas decreases. But for ultra-high swirl application, it may not be true. This is shown in the result below. From the literature study, a study focused specifically on ultra-high swirl flameless combustion was not found in any literature. Most of the swirl flow study involving combustion was performed in a relatively low $\left(S_{g}<10\right)$ compared to this work that involves $S_{g}>100$.

From the results, it can clearly be seen that as the number of injectors increase, the emission of $\mathrm{CO}$ gas decreased reassuringly until the production of $\mathrm{CO}$ was completely abated (emission of $\mathrm{CO}$ at $0 \mathrm{ppm}$ ), as shown in Figure 2. On the other hand, Figure 3 showed that the level of emission of $\mathrm{NO}_{x}$ gas were very close for $n \leq 9$. But interestingly as soon as $n=12$, the emission of $\mathrm{NO}_{\mathrm{x}}$ gas was completely abated (emission of $\mathrm{NO}_{x}$ at $0 \mathrm{ppm}$ ). These results are in line with previous studies [10].

From further investigation, Figure 4 and Figure 5 revealed that as the swirl number increased, the emission of $\mathrm{CO}$ and $\mathrm{NO}_{x}$ gas increased significantly. This is opposite to the initial assumption where it was shown in previous works, as the swirl increased, the emission of $\mathrm{NO}_{\mathrm{x}}$ and $\mathrm{CO}$ gas will be reduced [21]. It was obvious that $\mathrm{CO}$ emission increased significantly with the increase of swirl number. Whereas for the emission level of $\mathrm{NO}_{x}$ gas, a sudden increase was observed at $\left(\mathrm{S}_{\mathrm{g}} \leq 200\right)$, and emission level maintained in between $45 \sim 55 \mathrm{ppm}$ as the swirl number increases.

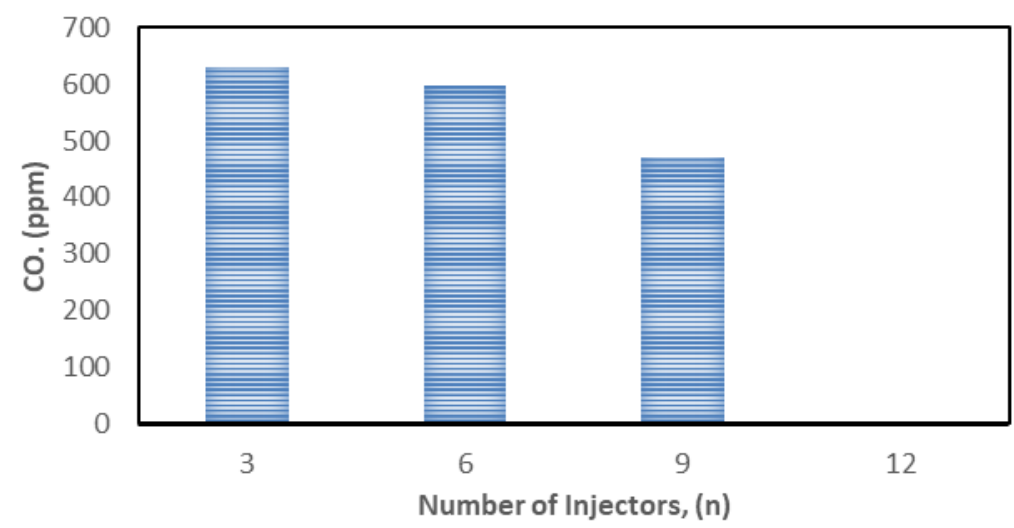

Fig. 2. Emission level of $\mathrm{CO}$ gas for different numbers of activated tangential injectors 


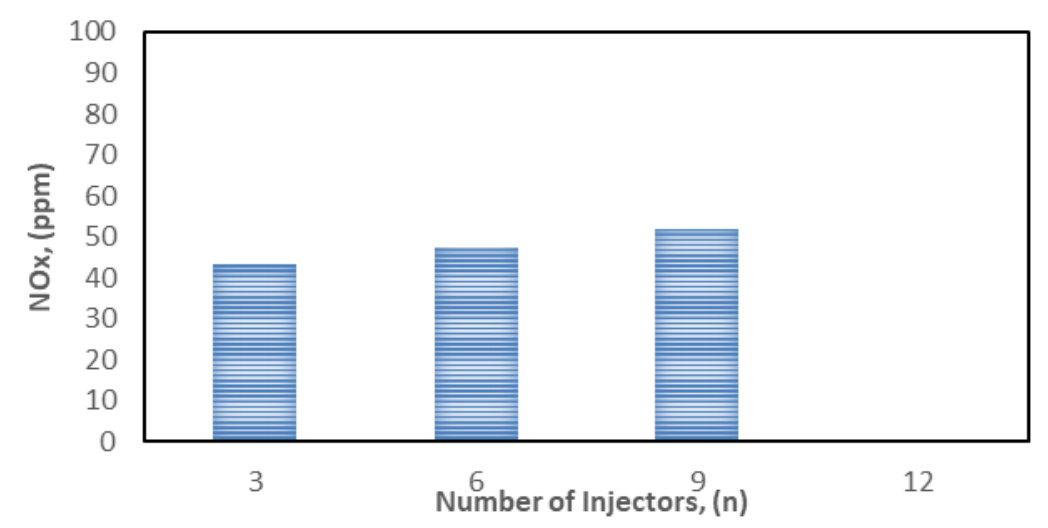

Fig. 3. Emission level of $\mathrm{NO}_{x}$ gas for different numbers of activated tangential injectors

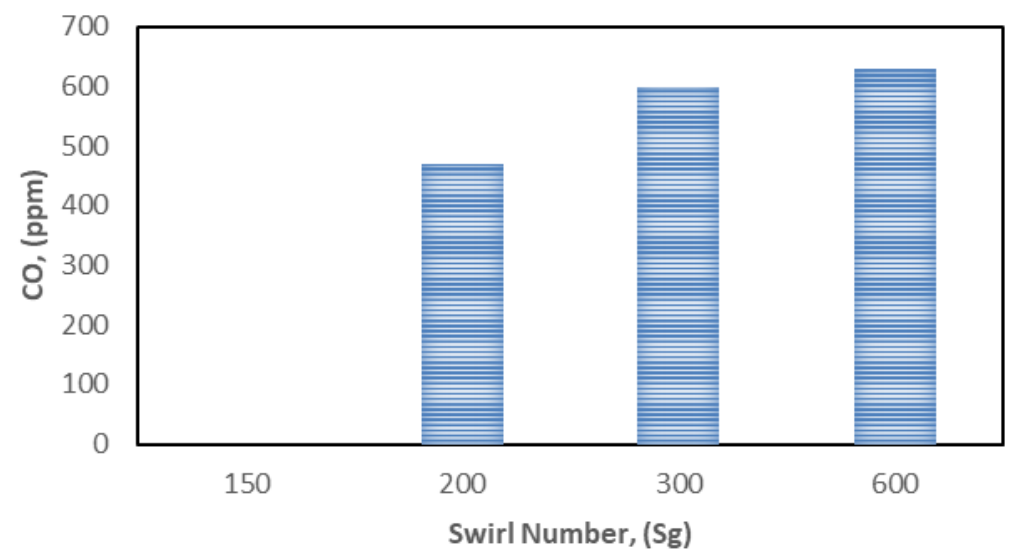

Fig. 4. Emission level of $\mathrm{CO}$ gas for different Swirl Numbers $\left(\mathrm{S}_{\mathrm{g}}\right)$

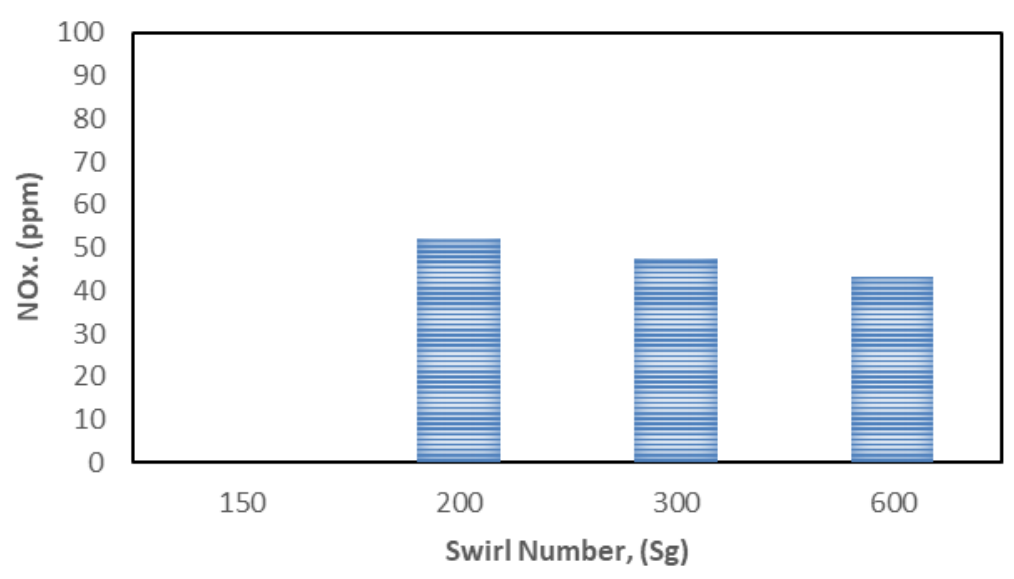

Fig. 5. Emission level of NOx gas for different Swirl Number (Sg)

It is worthy to note that although the emission level differs from each study case, all study case was recorded to successfully maintain flameless mode throughout the experiments. This can be supported by the fact that the temperature fluctuation inside the combustion chamber was relatively non-existent, as revealed by Figure 6 and Figure 7. From further inspection, the results also showed that the peak temperature remained relatively the same, with a difference of less than $50^{\circ} \mathrm{C}$ regardless of the swirl number. These two characteristics suit well into the behaviour of flameless combustion [31].

To further support this claim, Table 2 . lists the temperature uniformity $\left(R_{u}\right)$ inside the combustion chamber for all study case. As previously mentioned, as $R_{u}$ approaches zero, the temperature 
fluctuation inside the combustion chamber also reduces. Thus, the smaller the values of $R_{u}$ becomes, the more uniform the temperature profile inside the combustion chamber is. From Table 2, regardless of the number of the activated tangential inlets, or the swirl number, all the values of $R_{u}$ for every studied case are very small, which is a unique trait of flameless combustion. This indicates that a flameless environment was most likely maintained inside the combustion chamber.

Table 2

Temperature Uniformity for the various number of injectors

\begin{tabular}{lll}
\hline No. of Injectors & $\mathrm{S}_{\mathrm{g}}$ & Temperature uniformity, $\left(\mathrm{R}_{\mathrm{u}}\right)$ \\
\hline 3 & 600 & 0.053 \\
6 & 300 & 0.035 \\
9 & 200 & 0.042 \\
12 & 150 & 0.030 \\
\hline
\end{tabular}

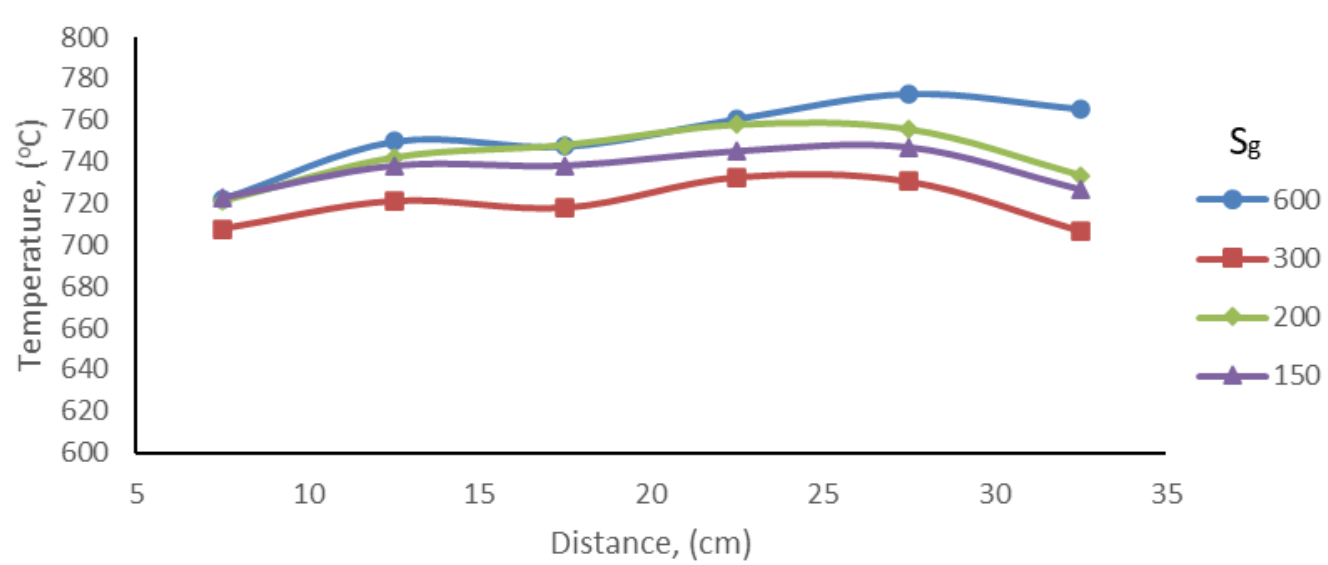

Fig. 6. Temperature profile for different geometrical swirl number (Sg)

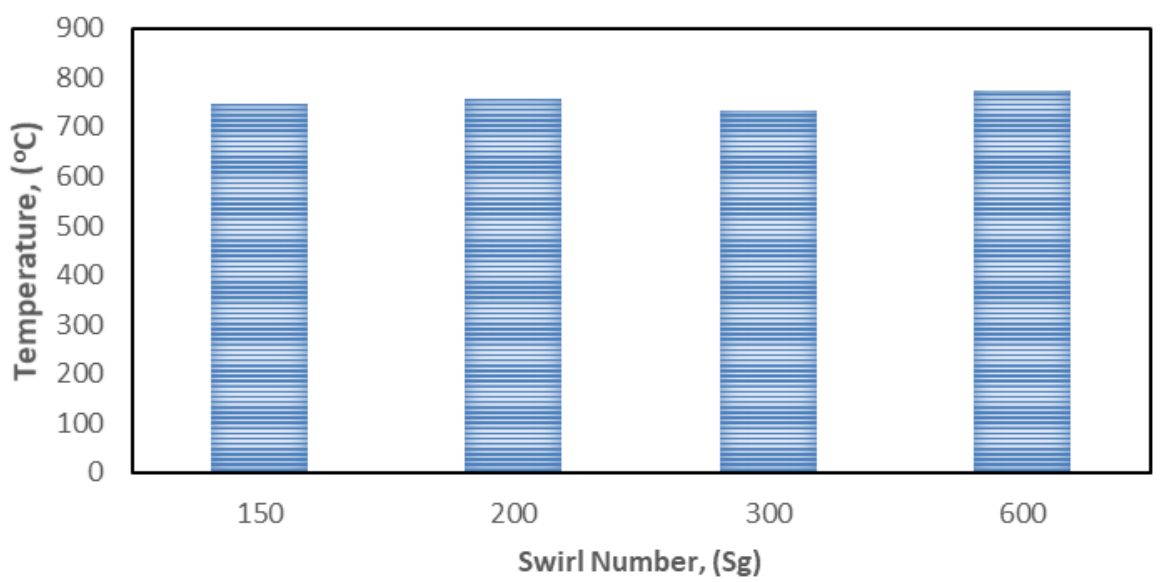

Fig. 7. Peak temperature at different geometrical swirl number $\left(\mathrm{S}_{\mathrm{g}}\right)$

Therefore, from the results shown above, it can be observed that too high of a level of swirl intensity with poor positioning of swirl generator reduces the efficiency of the combustion process, and produces an extremely high level of harmful gas emission, despite the fact that flameless mode was successfully maintained throughout the combustion process. It is worthy to note that flameless mode is known to reduce emission of NOx and CO gasses [32]. This rather contradictory result is most probably due to poor heat transfer in the combustion process. It is also believed that uneven mixing between the reactant mixture and flue gas inside the combustion chamber was also causing the emission level to increase despite the fact that high swirl flow exists inside the combustion chamber. 
By adding the number of tangential injectors and evenly dividing the swirl strength through the extra swirl generator circumferentially, the mixing of recirculated flue gas and unburned fuel mixture was optimized, improving the rate of combustion and thus, rapidly reducing the production of $\mathrm{CO}$ and $\mathrm{NO}_{x}$ gas substantially $[33,34]$.

\section{Conclusions}

This work has managed to experimentally proven a liquid fuelled combustion technique and concept, that has the capability of generating power with zero emission of both $\mathrm{CO}$ and $\mathrm{NO}_{\mathrm{x}}$ gases on a simple cylindrical shaped flameless combustor by utilising ultra-high swirl flow. This was made possible mainly due to two factors. The first factor is the fact that the peak temperature inside the combustion chamber was significantly lower compared to conventional combustion. This prevented thermal $\mathrm{NO}_{\mathrm{x}}$ formation to take place during the combustion process, and the same time, prevents dissociation of $\mathrm{CO}_{2}$ gas into $\mathrm{CO}$ gas caused by high temperature $[35,36]$. This is evident as flameless mode was established regardless of swirl number, and tangential air inlet (swirl generator injectors) configuration.

The second factor is the reinforcement of swirl flow from the reintroduction of swirl injector further downstream axially and also circumferentially. By doing so, it is believed to counter the effect of swirl decay throughout the whole volume of the combustion chamber and as a result, maximizes the entrainment of flue gas. This allowed for significant improvement in the mixing of unburned fuel in the flue gas with the fresh reactant's mixture for complete combustion. Thus, as a conclusion, for the sole purpose of optimization and reducing the emission of $\mathrm{CO}$ and $\mathrm{NO}_{\times}$gases of liquid fuelled flameless combustion, the number of injectors, and the location of swirl generator (tangential injection type) has a much more significant effect compared to the strength of the swirl.

\section{Acknowledgement}

This research was funded by Transdisciplinary Research Grant, UTM-TDR vote no. 07g04.

\section{References}

[1] Fenger, Jes. "Air pollution in the last 50 years-From local to global." Atmospheric environment 43, no. 1 (2009): 1322. https://doi.org/10.1016/i.atmosenv.2008.09.061

[2] Susanto, Asep Kadarohman, Fitri Khoerunnisa, and Ratna Eko Sardjono. "The Effects of Using Diesel-Citronella Fuel Blend on The Emission and Fuel Consumption for Single-Cylinder Diesel Engine." Journal of Advanced Research in Fluid Mechanics and Thermal Sciences 74, no. 2 (2020): 1-15.

https://doi.org/10.37934/arfmts.74.2.115

[3] Luhmann, H., F. Carrasco Maldonado, R. Spörl, and G. Scheffknecht. "Flameless Oxidation of liquid fuel oil in a reverse-flow cooled combustion chamber." Energy Procedia 120 (2017): 222-229. https://doi.org/10.1016/j.egypro.2017.07.168

[4] Sies, Mohsin Mohd, and Mazlan Abdul Wahid. "Numerical Investigation of the Asymmetrical Vortex Combustor Running on Biogas." Journal of Advanced Research in Fluid Mechanics and Thermal Sciences 74, no. 1 (2020): 1-18. https://doi.org/10.37934/arfmts.74.1.118

[5] Maksom, Mohammad Syahadan, Nurul Fitriah Nasir, Norzelawati Asmuin, Muhammad Faqhrurrazi Abd Rahman, and Riyadhthusollehan Khairulfuaad. "Biodiesel Composition Effects on Density and Viscosity of Diesel-Biodiesel Blend: A CFD Study." CFD Letter 12, no. 4 (2020): 100-109. https://doi.org/10.37934/cfdl.12.4.100109

[6] Cavaliere, Antonio, and Mara de Joannon. "Mild combustion." Progress in Energy and Combustion science 30, no. 4 (2004): 329-366.

https://doi.org/10.1016/i.pecs.2004.02.003

[7] Sorrentino, G., U. Göktolga, M. De Joannon, J. Van Oijen, A. Cavaliere, and P. De Goey. "An experimental and numerical study of MILD combustion in a Cyclonic burner." Energy Procedia 120 (2017): 649-656. 
https://doi.org/10.1016/i.egypro.2017.07.173

[8] Cheong, Kin-Pang, Guochang Wang, Bo Wang, Rong Zhu, Wei Ren, and Jianchun Mi. "Stability and emission characteristics of nonpremixed MILD combustion from a parallel-jet burner in a cylindrical furnace." Energy 170 (2019): 1181-1190. https://doi.org/10.1016/j.energy.2018.12.146

[9] Derudi, Marco, and Renato Rota. "Experimental study of the mild combustion of liquid hydrocarbons." Proceedings of the Combustion Institute 33, no. 2 (2011): 3325-3332.

https://doi.org/10.1016/i.proci.2010.06.120

[10] Wünning, J. "Flameless oxidation." In 6th HiTACG Symposium, Essen, Germany. 2005.

[11] Kasani, Adam, Mazlan Abdul Wahid, Muhammad Amri Mazlan, Aminuddin Saat, and Mohd Yasin. "On the effects of fuel inlet configurations and equivalence ratio to the pre-heating stage of a liquid fuelled flameless swirl combustor." In AIP Conference Proceedings, vol. 2062, no. 1, p. 020040. AIP Publishing LLC, 2019. https://doi.org/10.1063/1.5086587

[12] Wünning, J. A., and J. G. Wünning. "Flameless oxidation to reduce thermal NO-formation." Progress in energy and combustion science 23, no. 1 (1997): 81-94. https://doi.org/10.1016/S0360-1285(97)00006-3

[13] Noor, M. M., Andrew P. Wandel, and Talal Yusaf. "MILD combustion: the future for lean and clean combustion technology." International Review of Mechanical Engineering 8, no. 1 (2014): 251-257. https://doi.org/10.15866/ireme.v8i1.1267

[14] Kasani, Adam, Mazlan Abdul Wahid, Muhammad Amri Mazlan, Aminuddin Saat, and Mohd Yasin. "Development of liquid fueled flameless combustor." In AIP Conference Proceedings, vol. 2062, no. 1, p. 020041. AIP Publishing LLC, 2019.

https://doi.org/10.1063/1.5086588

[15] Weihong, Yang, and Blasiak Wlodzimierz. "CFD as applied to high temperature air combustion in industrial furnaces." IFRF Combustion Journal 2006 (2006): 1-22.

[16] Al Wan, Raid Abid. "Thermal and Fluid Flow Analysis of Swirling Flameless Combustion." PhD diss., Universiti Teknologi Malaysia, 2016.

[17] Abuelnuor, Abuelnuor Abdeen Ali. "Thermal characteristics and emissions of gaseous fuel flameless combustion with tangential air inlet." PhD diss., Universiti Teknologi Malaysia, 2014.

[18] Weber, Roman, John P. Smart, and Willem vd Kamp. "On the (MILD) combustion of gaseous, liquid, and solid fuels in high temperature preheated air." Proceedings of the Combustion Institute 30, no. 2 (2005): 2623-2629. https://doi.org/10.1016/i.proci.2004.08.101

[19] Danon, Bart, E-S. Cho, Wiebren de Jong, and D. J. E. M. Roekaerts. "Parametric optimization study of a multi-burner flameless combustion furnace." Applied thermal engineering 31, no. 14-15 (2011): 3000-3008. https://doi.org/10.1016/i.applthermaleng.2011.05.033

[20] Mahalegi, Hamed Karimi Motaalegh, and Amir Mardani. "Investigation of fuel dilution in ethanol spray MILD combustion." Applied Thermal Engineering 159 (2019): 113898. https://doi.org/10.1016/j.applthermaleng.2019.113898

[21] Reddy, V. Mahendra, Darshan Sawant, Darshan Trivedi, and Sudarshan Kumar. "Studies on a liquid fuel based two stage flameless combustor." Proceedings of the Combustion Institute 34, no. 2 (2013): 3319-3326. https://doi.org/10.1016/i.proci.2012.06.028

[22] Reddy, V. Mahendra, Darshan Trivedi, Darshan Sawant, and Sudarshan Kumar. "Investigations on emission characteristics of liquid fuels in a swirl combustor." Combustion Science and Technology 187, no. 3 (2015): $469-488$. https://doi.org/10.1080/00102202.2014.956098

[23] Ye, Jingjing, Paul R. Medwell, Emilien Varea, Stephan Kruse, Bassam B. Dally, and Heinz G. Pitsch. "An experimental study on MILD combustion of prevaporised liquid fuels." Applied Energy 151 (2015): 93-101. https://doi.org/10.1016/i.apenergy.2015.04.019

[24] Jumadi, Rozita, Amir Khalid, Norrizam Jaat, Iqbal Shahridzuan Abdullah, Nofrizalidris Darlis, Bukhari Manshoor, Azahari Razali, Azwan Sapit, and Ridwan Saputra Nursal. "Analysis of Spray Characteristics and High Ambient Pressure in Gasoline Direct Injection using Computational Fluid Dynamics." CFD Letter 12, no. 5 (2020): 36-51. https://doi.org/10.37934/cfdl.12.5.3651

[25] Islek, Akay Aydin. "The impact of Swirl in Turbulent Pipe flow." PhD diss., Georgia Institute of Technology, 2004.

[26] Guo, H. F., Z. Y. Chen, and C. W. Yu. "Simulation of the effect of geometric parameters on tangentially injected swirling pipe airflow." Computers \& fluids 38, no. 10 (2009): 1917-1924. https://doi.org/10.1016/i.compfluid.2009.05.001

[27] Guo, Z., and V. K. Dhir. "Single-and two-phase heat transfer in tangential injection-induced swirl flow." International Journal of Heat and fluid flow 10, no. 3 (1989): 203-210. 
https://doi.org/10.1016/0142-727X(89)90039-8

[28] Jarpala, Raghu, Naga Venkata Sai Aditya Burle, Mourya Voleti, and Rajesh Sadanandan. "Effect of swirl on the flame dynamics and pollutant emissions in an ultra-lean non-premixed model gas turbine burner." Combustion Science and Technology 189, no. 10 (2017): 1832-1848.

https://doi.org/10.1080/00102202.2017.1333500

[29] Tangirala, V., R. H. Chen, and James F. Driscoll. "Effect of heat release and swirl on the recirculation within swirlstabilized flames." Combustion science and technology 51, no. 1-3 (1987): 75-95. https://doi.org/10.1080/00102208708960316

[30] Tangirala, V., and J. F. Driscoll. "Temperatures within non-premixed flames: effects of rapid mixing due to swirl." Combustion science and technology 60, no. 1-3 (1988): 143-162.

https://doi.org/10.1080/00102208808923981

[31] Ellis, William, William Lear, Bhupinder Singh, Aditya Srinivasan, John Crittenden, and S. A. Sherif. "Flameless combustion of biofuels in a semi-closed cycle gas turbine." In 46th AIAA aerospace sciences meeting and exhibit, p. 1140. 2008.

https://doi.org/10.2514/6.2008-1140

[32] Cerea, M., Marco Derudi, and Renato Rota. "Preliminary Study On Mild Combustion Characteristics of a Liquid Biofuel." In The Thirty-fifth Meeting of the Italian Section of the Combustion Institute, Milano, Oct, pp. 10-12. 2012.

[33] Bali, Tulin, and Betul Ayhan Sarac. "Experimental investigation of decaying swirl flow through a circular pipe for binary combination of vortex generators." International Communications in Heat and Mass Transfer 53 (2014): 174179.

https://doi.org/10.1016/i.icheatmasstransfer.2014.02.030

[34] Saraç, Betül Ayhan, and Tulin Bali. "An experimental study on heat transfer and pressure drop characteristics of decaying swirl flow through a circular pipe with a vortex generator." Experimental Thermal and Fluid Science 32, no. 1 (2007): 158-165. https://doi.org/10.1016/i.expthermflusci.2007.03.002

[35] Khalil, Ahmed EE, Vaibhav K. Arghode, Ashwani K. Gupta, and Sang Chun Lee. "Low calorific value fuelled distributed combustion with swirl for gas turbine applications." Applied energy 98 (2012): 69-78. https://doi.org/10.1016/i.apenergy.2012.02.074

[36] Khalil, Ahmed EE, and Ashwani K. Gupta. "Hydrogen addition effects on high intensity distributed combustion." Applied energy 104 (2013): 71-78. https://doi.org/10.1016/j.apenergy.2012.11.004 